\title{
CONGENITAL FIBROCYSTIC LIVER DISEASE. Imaging features and differential diagnosis
}

E. Inchausti, I. Barral, M. Zubizarreta, A. Goienetxea Murgiondo, A. Ugarte Nuño, A. Astiazaran Rodríguez; Radiology department; Universitary Hospital Donostia/ES. Osatek Donostia.
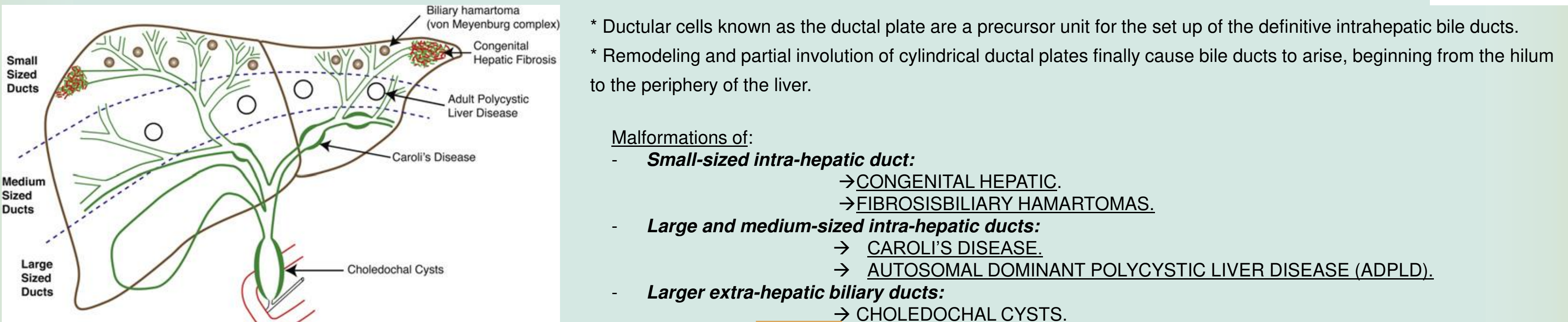

\section{CONGENITAL HEPATIC FIBROSIS:}

AUTOSOMAL RECESSIVE POLYCYSTIC DISEASE (ARPKD)

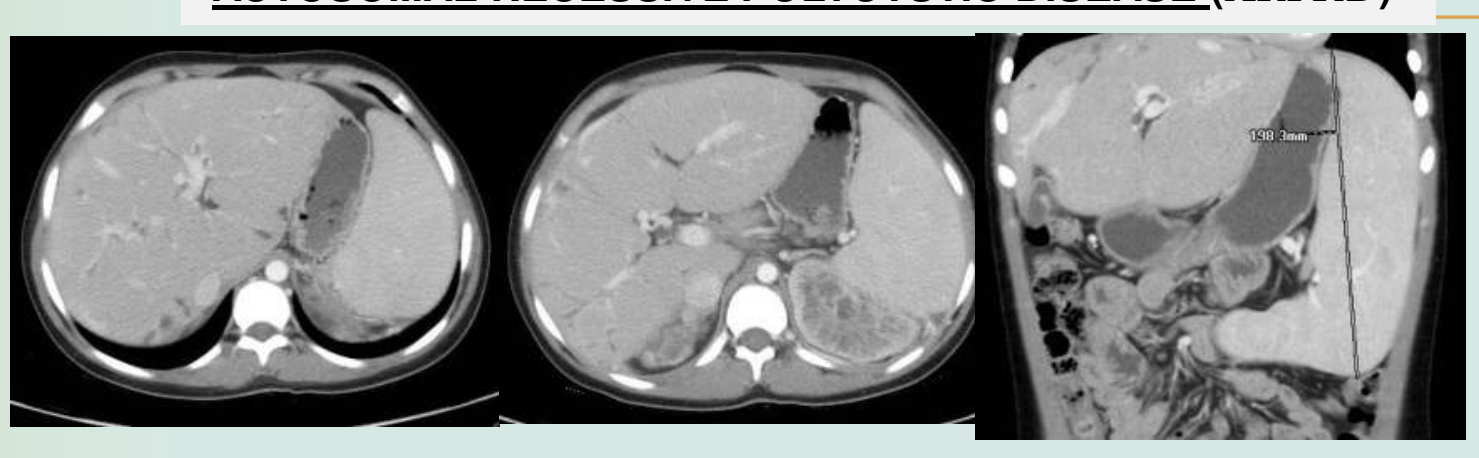

Some distinct CT features:

Hypertrophic left lateral segment. Normal or hypertrophic left media segment.

Atrophic right lobe.

Varices, splenomegaly, associated ducta plate malformations, and renal abnormalities.
DIFERENTIAL DIAGNOSIS: CIRRHOSIS

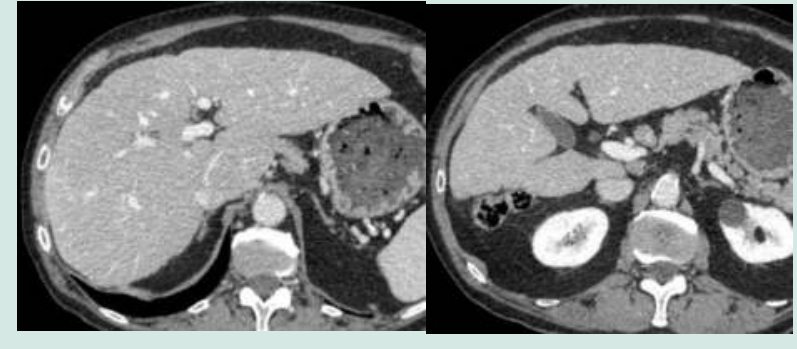

Medial segment is normal in size or enlarged in congenital hepatic fibrosis, but is usually small in patients with cirrhosis due to other causes.

\section{BILIARY HAMARTOMAS:}

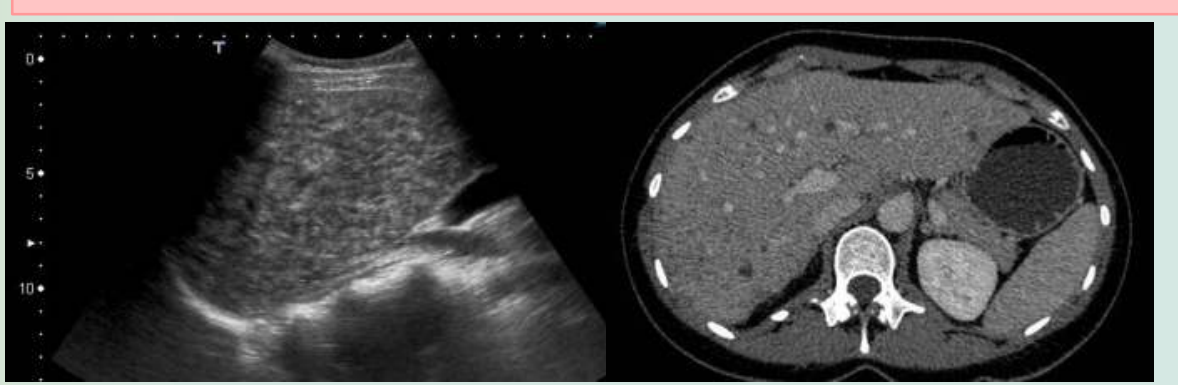

On ultrasound: Tiny hypoechoic or hyperechoic foci measuring less than $10 \mathrm{~mm}$ and distributed uniformly throughout the liver, and may demonstrate comet-tail artefacts.

On CT: low-attenuation, non-enhancing lesions.

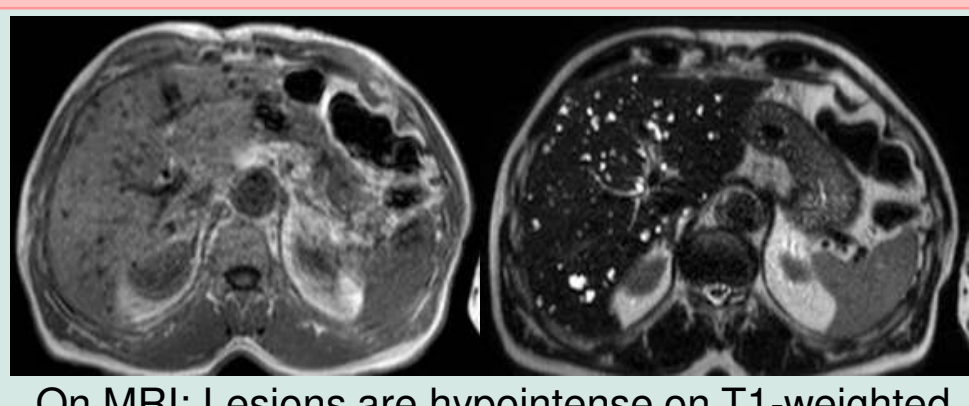

On MRI: Lesions are hypointense on T1-weighted and hyperintense on T2-weighted images.

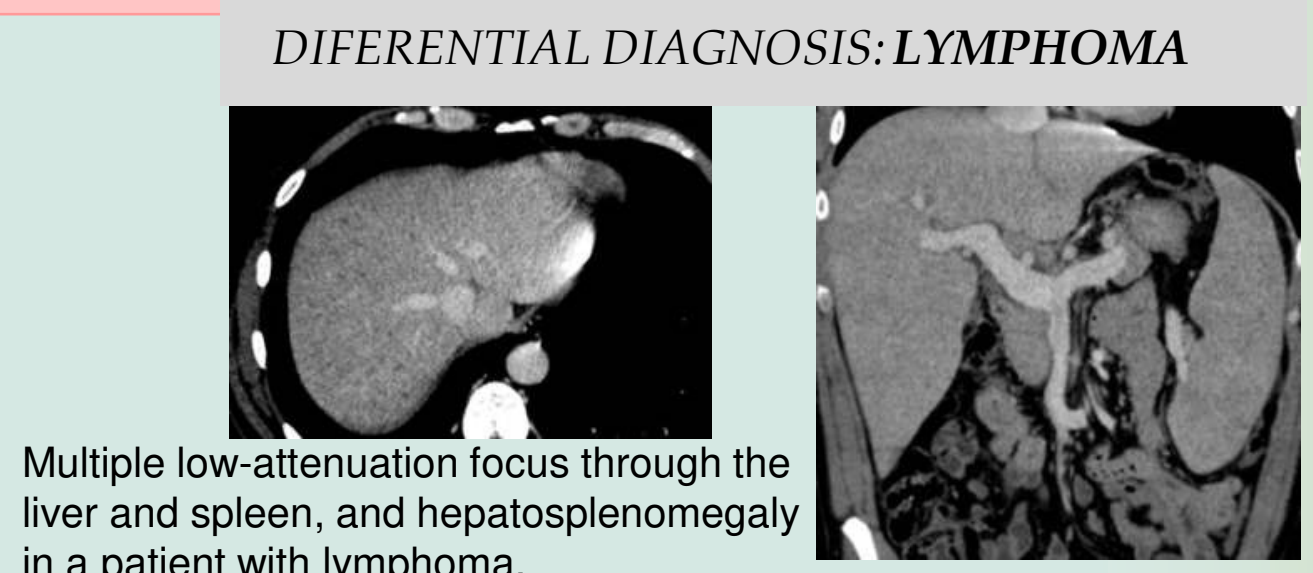

in a patient with lymphoma.

\section{AUTOSOMAL DOMINANT POLYCYSTIC DISEASE:}

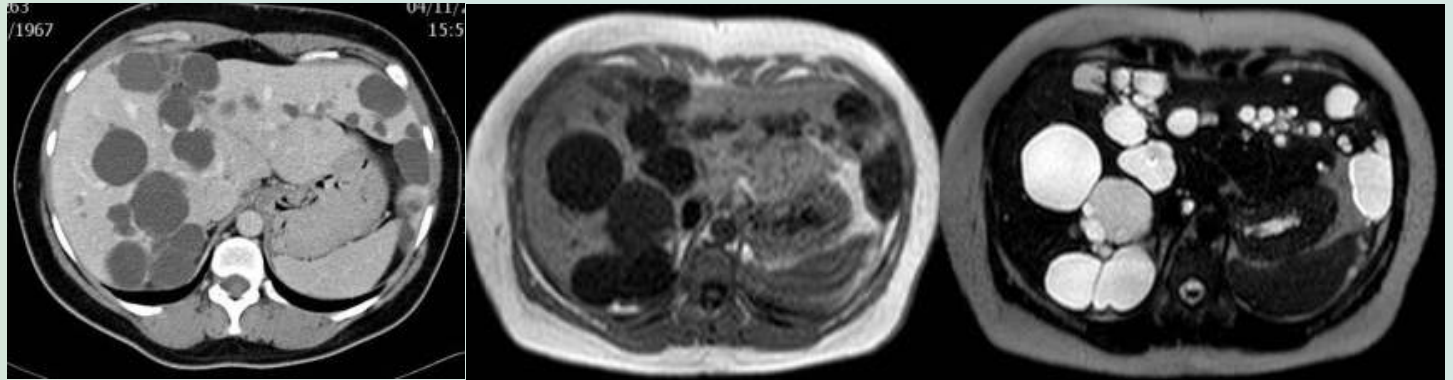

AUTOSOMAL DOMINANT POLYCYSTIC LIVER DISEASE (ADPLD) CT shows multiple cysts with low attenuation.

MRI: T1-weighted imaging demonstrates low signal intensity fluid-containing cysts, while T2-weighted imaging shows cysts with high signal intensity.

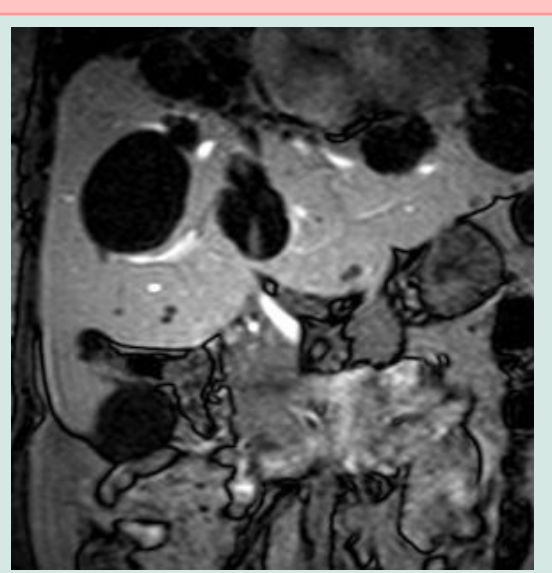

MRI: Contrast enhancement (multihance) delayed seccuences confirms the absence of communication between the biliary tree and the cystic lessions.

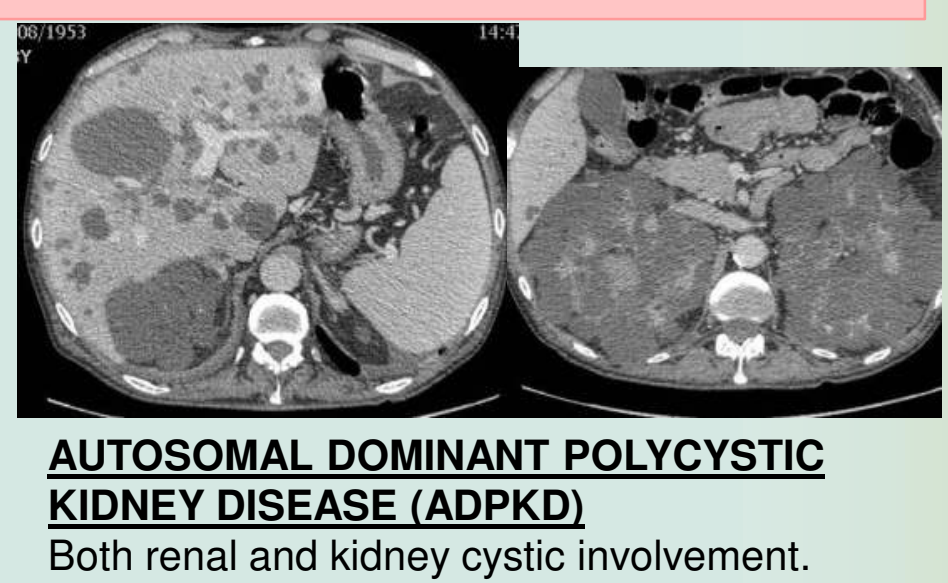

\section{CAROLI DISEASE:}

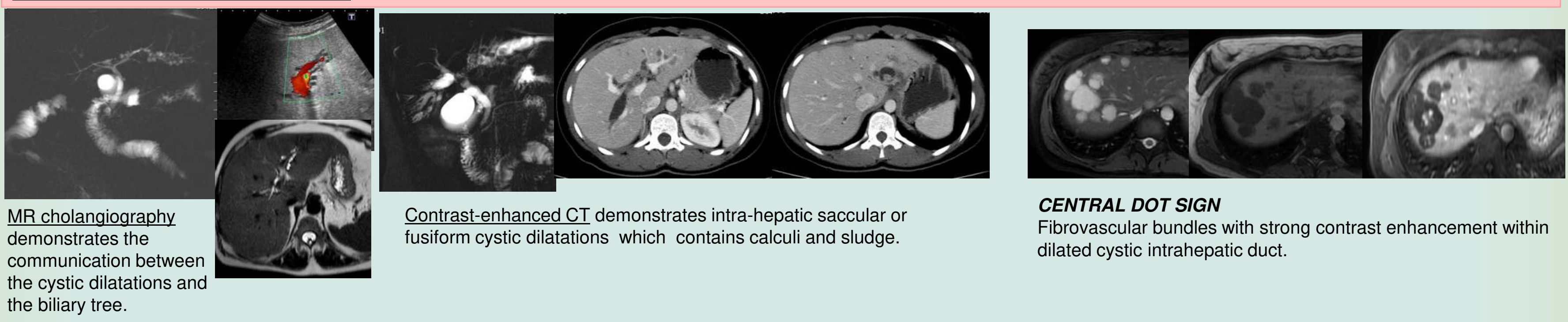

\section{CHOLEDOCHAL CYSTS:}
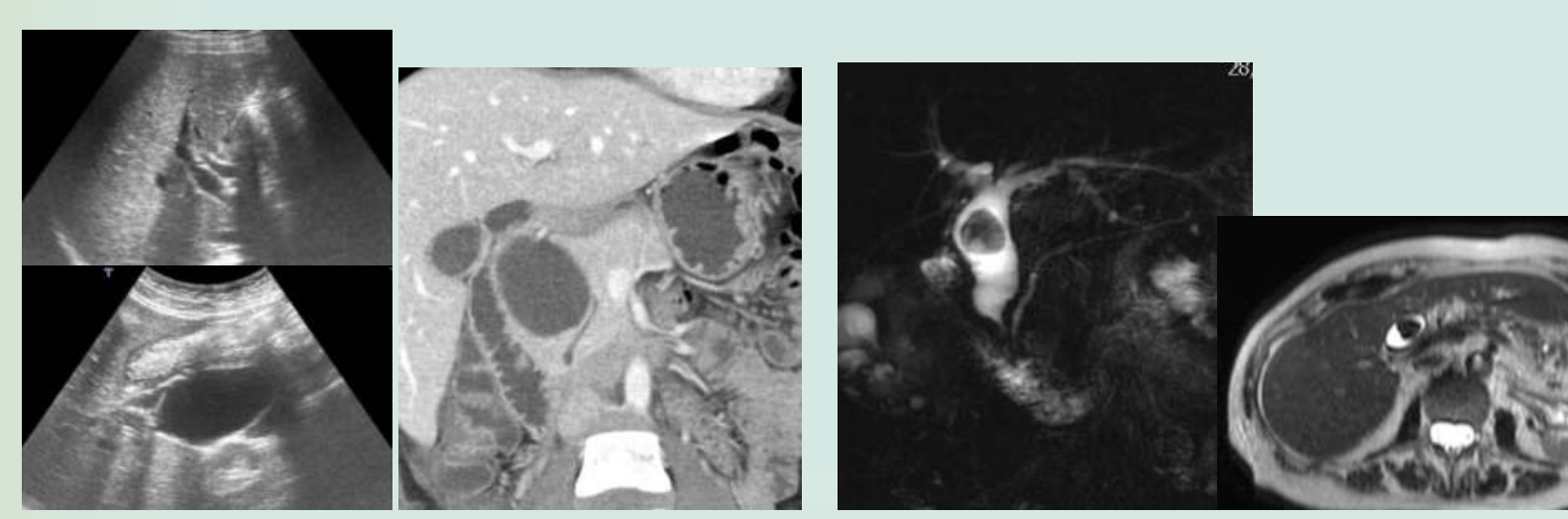

TYPE I:Cystic or fusiform dilatation of the extrahepatic common bile duct.

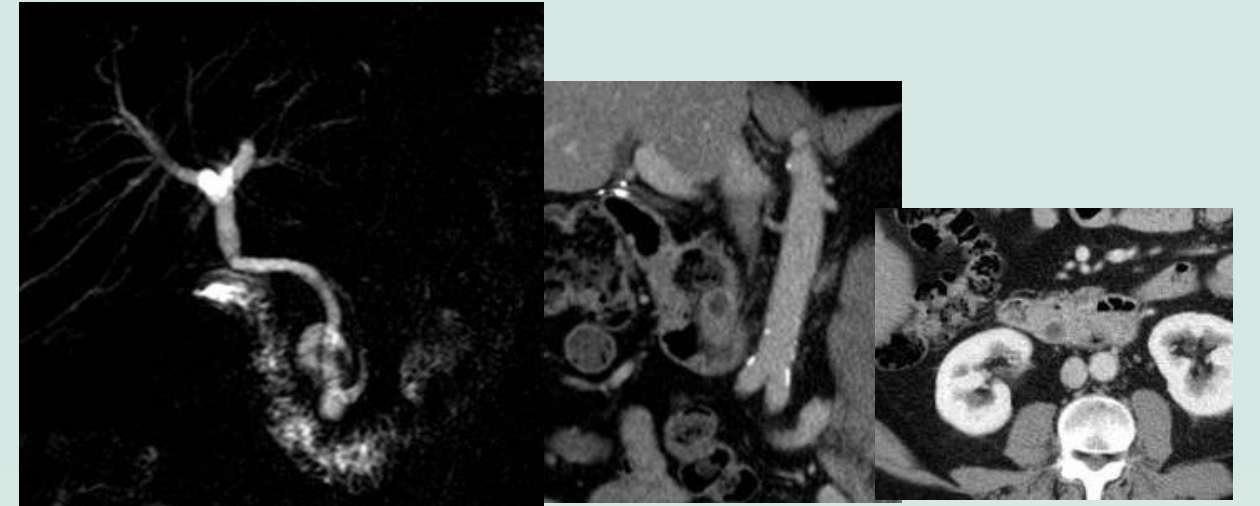

TYPE III: CT shows periampullary cystic dilatation of the extrahepatic common bile duct.

The presence of an adyacent duodenum diverticulum is noted

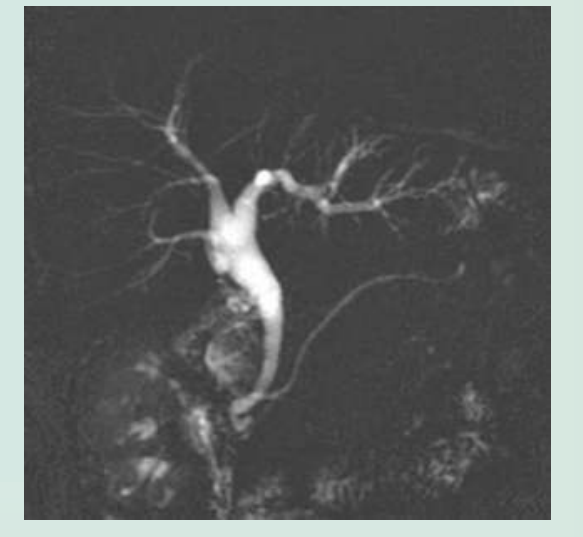

TYPE IV: Combination of both intrahepatic and extrahepatic bile duct dilatation 